\title{
E-learning Opportunities and Limitations in Inclusive Higher Education
}

\author{
Svetlana Ponomareva ${ }^{1, *}$ and Ekaterina Ugnich $^{1,2}$ \\ ${ }^{1}$ Don State Technical University, 1 Gagarin sq. Rostov-on-Don, Russia \\ ${ }^{2}$ Departament of World Economy
}

\begin{abstract}
The objective of this work is to study the limitations and opportunities for e-learning development in the inclusive education system in higher education establishments. To determine the possibility of e-learning application in inclusive higher education, the principles of evolutionary economics and institutional theory were used. It is shown that e-learning development in the national higher education system and its perception by the higher inclusive education system depends on the development level of social and information interrelations in society. Moreover, elearning application in inclusive higher education is possible only in collaboration with traditional learning. E-learning efficiency in inclusive higher education depends on institutional environment existing both at state level and separate university level. Herewith, institutional environment should be aimed not only at e-learning development and inclusive education, but also their collaboration. The results achieved are verified by empirical study of e-learning implementation into the inclusive higher education system by the example of Russia. The results of the conducted research, which indicated peculiarities, opportunities and limitations of an e-learning mechanism in inclusive higher education, can be applied to increase its efficiency both at separate universities level and at the level of state strategies formation for higher education development.
\end{abstract}

\section{Introduction}

Modern transformation of digital environment influences the e-learning development supplementing it with new technologies and methods. The advantages of e-learning generate also high demand for it in terms of solving important social problems [1;2], in particular, overcoming inequality of students' physical abilities. Nowadays, e-learning is largely used in inclusive education aimed at educating people with special healthcare needs. However, inclusive education due to its specificity has special requirements for the mechanisms and principles of learning in general and elearning in particular. In addition, e-learning development in inclusive education is significantly influenced by the national strategy for education development [3], as well as systemic changes in global digital environment [4]. Therefore, it is necessary to assess the prospects and determine the limits of elearning application in inclusive education taking into account national institutional conditions. Such question statement is an attempt to broaden e-learning concept understanding and its applicability in inclusive education. In this regard, it is necessary to proceed from the understanding of e-learning dual nature which, on the one hand, implies progressive inception [5], influencing the development of the entire higher education system, and, on the other hand, is a destructive form of innovation [6] in higher education establishments. Dichotomous e-learning content understanding, amplified by the influence of institutional national policy [7], can play an important role in the development of inclusive education practice in higher education establishments. The objective of this work is to study the limitations, opportunities and prospects of e-learning in the inclusive education system in higher education establishments.

\section{Content and research methods}

In the focus of this study is the analysis of opportunities and prospects of e-learning as a tendency of educational environment development in universities for students with special healthcare needs. As conceptual framework for considering inclusive higher education served the socially-centered approach (social model) $[8 ; 9]$ to understand limited abilities of human health. This research is based on the systematic approach $[10 ; 11 ; 12]$ to understand inclusive higher education and e-learning. Moreover, the principles of evolutionary economy consolidation [13] and institutional theory [14] are the research bases according to which institutions that possess maximum set of favorable properties, which contribute to effective development of society and economy, are preserved and gain further developed. The study of e-learning development in inclusive higher

\footnotetext{
* Corresponding author: ugnich77@ mail.ru
} 
education on the example of Russia confirmed the importance of institutional environment for their synthesis' effects amplification.

\section{Research results}

\subsection{Evolution of e-learning in higher education}

The education system, which is constantly updated in accordance with social demands, has always been searching for the most progressive teaching methods. Thus, at the end of the twentieth century there was the elearning system as a way of learning with the help of the Internet and multimedia. According to M. Laanpere's genealogical research $[15 ; 16]$ it is distance education that is at the heart of e-learning development. Since elearning is in direct correlation with the development of information and communication technologies, its evolution can be traced in accordance with the Internet (web) environment development, its design change, structure and content. E-learning evolution in accordance with web development is presented in Fig.1.

Let us give a brief description of e-learning development stages presented in Fig.1. If e-learning 1.0, based on web1.0, a read-only or web-static information network, provides only content, and teaching process here is similar to an instructor-led class, e-learning 2.0, on the contrary, has the ability to inform, work and, to a certain degree, connect people with each other. Elearning 2.0, with the exception of LMS and LCMS, includes blogs, e-portfolios, and social networks (Vkontakte, Facebook, etc.). Since 2008, a brand-new digital practice emerges - mass open online courses (MOOC) [4], for example, Coursera, Udacity, Openedu, the popularity of which is noted at present. E-learning 3.0 is based on the mobile Internet and mobile teaching created on its platform, as well as on the used cloud and added and virtual reality (AR / VR) technologies. The prognosticated stage of further development is e-leaning 4.0 , built on web 4.0 or NeuroNet. At the core of web 4.0 there is the principle of neurocommunication, based on the idea of enhancing human intelligence [17] by analogy with physical strength amplification. The key principles of e-leaning 4.0 are self-learning and selforganization.

The popularity of e-learning can be evidenced by the fact that by now more than 40 million students around the world have used the online learning form [18]. Global e-learning market indicators speak volumes on the "turbulent" current development of e-learning. Thus, its average growth rate for five years constituted 9.2\%. At the same time, the highest growth rate of e-learning market is observed in the countries of Asia and Eastern Europe: China (52\%), Malaysia (41\%), Romania (38\%), Poland (28\%), the Czech Republic (27\%). It should be noted that state policy has a certain impact on e-learning development. By the way, in Romania as well as in Poland, and the Czech Republic, although there is no independent e-learning development strategy, state support is provided on permanent basis.

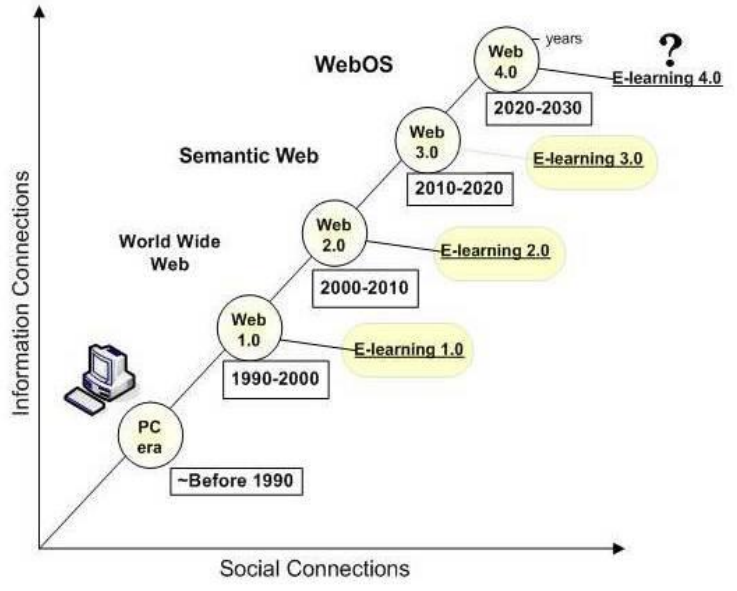

Fig. 1. Web and e-learning evolution.

On the one hand, among indisputable e-learning advantages for higher education it is appropriate to distinguish time and costs' saving for training, flexibility and accessibility of training format, facility of teaching material actualization, teaching process transparency, rapid availability of statistics for result analysis. Besides, the non-linearity of teaching, which is based on the use of special methods, forms the student's ability to perceive the necessary information in proper place and at proper time. On the other hand, e-learning in higher education establishments can be considered as subversive innovation, and its implementation can cause resistance on teachers' part [2].

\subsection{E-learning in inclusive higher education (Russian experience)}

E-learning due to its flexibility performs an important social function making education accessible for different groups of people. In educational systems of many countries e-learning advantages were also directed at solving problems of people with special healthcare needs, and, in particular, at inclusive education development. Inclusive education is a new stage in education development implying its accessibility for students with special healthcare needs in terms of adapting it to their various needs. In modern conditions, inclusive education development is caused primarily due to the growth in number of people with special healthcare needs. So, according to statistical data of the World Health Organization, in the world disabled people make up $23 \%$ of the total population of the planet that is more than 1 billion people. Inclusions in society, overcoming social and cultural barriers by the students with special healthcare needs are important components of inclusive higher education. A certain role can be played here by e-learning. So, virtual reality as an elearning tool 3.0 is simultaneously the technology for space transformation and the tool for overcoming existing forms of inequality, including physical limitations caused by human abilities. Its significance is much broader than technology for entertainment industry. It is seen as technology with serious potential 
to be used as a form of social communication and cultural adoption of reality [19].

VR technology development towards a greater immersion brings us closer to the solution of the problem of overcoming of physical abilities inequality, but still does not solve it. In addition, there are systemic limitations to the use of e-learning in inclusive higher education. Thus, Martins \& Nunes' research [8] demonstrated that the connection between the use of the latest achievements of ICT, e-learning tools and improvement in information perception by the students, increase in their training quality does not always exist. In a number of cases, the students find just simply an easier way to learn using ICT. The students must be taught to manage information and develop their communication skills. Another e-learning problem in higher education is the need in constant adaptation of university environment to a permanent e-learning environment renewal [20]. There also exist a certain problem of trust to e-learning in terms of gaining professional knowledge and skills. Overcoming these limitations is facilitated by the formation of favorable institutional environment for e-learning development in inclusive higher education and identification of state policy priorities in this field.

In Russia in inclusive higher education the experience of e-learning implementation has a relatively short history of development. The interest towards Russian experience is conditioned primarily by its unique retrospective. On the one hand, the traditional Russian education system was considered one of the best last century, and, on the other hand, the mass transition of Russian society to technological development began rather late - only in the late 90s of the XX century. Modern institutional environment for Russian e-learning is constituted by general legislative and regulatory framework for education in common. Inclusive education development is also facilitated by general regulatory and legal acts in the sphere of education and social welfare.

Despite the fact that legislative basis of inclusive education and e-learning was formed simultaneously, strategic development of inclusive education in Russia is focused more on the implementation of more general directions, particularly:

- provision of architectural accessibility in higher educational establishments;

- teachers' training for work in inclusive groups;

- assistance organization for people with special healthcare needs in higher educational establishments.

In recent years, in Russia there has been observed an increase in number of students with special healthcare needs; the share of total number of the people with special healthcare needs ranging from 18 to 30 years old makes $8 \%$. To compare, total proportion of young people, ranging from 18 to 30 years old, who get higher education in Russia constitutes $30 \%$. The dynamics of admission and total number of the students with special healthcare needs in Russian higher educational establishments is shown in Fig. 2.

Systemic implementation of inclusive education practice and its e-learning maintenance is extremely uneven in Russian higher educational establishments. In large universities, concentrated mainly in the capital, these processes are moving more intensively than in some other regions. As far as e-learning technical maintenance is concerned, it is noted that only $88.7 \%$ of the universities have fixed the broadband Internet. The state of e-learning technical side partly contributes to the fact that Russian education is dominated by e-learning 2.0 model, built primarily on web 2.0 technology, when the content is created by the users themselves. The complexity of transition to the model based on web 3.0 is evidenced by Russian e-learning technical equipment. Thus, for instance, only $46.2 \%$ of university employees use the Internet in their activities without which simultaneous training, being the most important condition for web 3.0, is impossible.

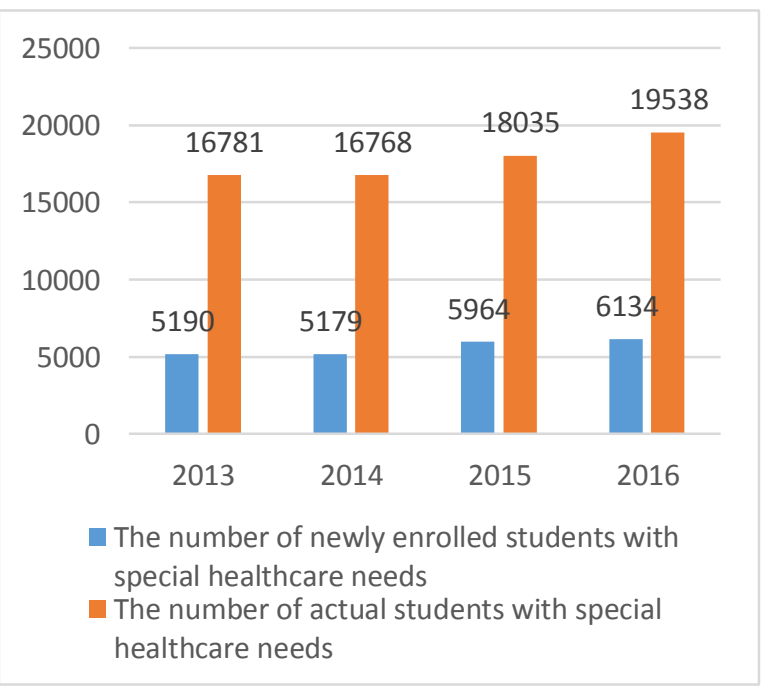

Fig.2. The dynamics of admission and total number of the students with special healthcare needs in Russian higher educational establishments (according to the Ministry of Education and Science of the Russian Federation).

Undoubtedly, successful education of the students with special healthcare needs depends directly on inclusive education conditions created by the educational organization [21]. But sole existence of specialized infrastructure in higher educational establishment is not enough. It has to be an organized modern training system on higher education programs with special equipment and software, tutorial maintenance, and e-learning usage. Thus, it is e-learning development that largely facilitates realization of these demands and inclusion of the students with special healthcare needs in educational environment.

At the same time, inclusive education cannot be built solely on e-learning methods. The individual training approach ensuring professional knowledge, skills and competencies acquisition, socialization problems solution for students with special healthcare needs and disabilities can be realized only in conditions of symbiosis of traditional teaching methods built on direct interaction according to the pattern "student-teacher" with e-learning methods. For inclusive education, the following indisputable e-learning advantages necessitate their usage: 
- general accessibility of training by creating virtual environment;

- collaboration for students with special healthcare needs and disabilities with other students and teachers by organizing training groups in electronic space;

- support and assistance provision for students with special healthcare needs and disabilities in the process of training and teachers in organization of electronic teaching process by creating specialized university structures;

- the most optimal use of available university resources and services necessary for application in electronic teaching and inclusive education.

But, nevertheless, the main problems of inclusive elearning education provision cannot be solved by administrative measures and regulations [8]. The main problematic issue here is not the choice of e-learning form, but its purpose in education, the benefits for students with special healthcare needs and society on the whole. The answers to these questions depend on the prevailing concepts of higher education functional role in society.

\section{Conclusion}

It should be noted that, on the one hand, this research allowed one to consider e-learning from web environment evolution standpoint that is its technical basis. On the other hand, the needs of society for provision of access to education, including higher education, for people with special healthcare needs put forward new demands for e-learning development and adaptation. E-learning advantages and disadvantages are first and foremost determined by the ability to transfer various forms of knowledge and the possibility of collaborations for students with special healthcare needs with teachers and other students that creates certain conditions for their socialization. In this connection, it can be concluded that e-learning can be rather efficient for inclusive education but mainly in combination with traditional teaching mode. Russian experience research on e-learning development and inclusive education showed the necessity for systemic institutional environment availability that creates the conditions for their further development and synthesis.

\section{References}

1. C Abbott. E-inclusion: Learning Difficulties and Digital Technologies (Bristol: Futurelab Education, 2007)

2. J.T Martins, M.B. Nunes, Learn. Organiz 23(5), 299-331 (2016)

3. M. Gaebel, V. Kupriyanova, R. Morais, E.Colucci, E-learning in European Higher Education Institutions. (Brussels, EUA, 2014)

4. G. Mozhaeva. SHS Web of Conferences 26, 01018 (2016)

5. M.A. McPherson, J.M. Nunes, J. Comput. Assist. Lear 24 (5), 433-455. (2008)
6. G. Hardaker, G. Singh, Campus-Wide Information Systems 28(4), 221-233. (2011)

7. G. Parchoma, Adoption of Technology Enhanced Learning in Higher Education: Influences of Institutional Policies and Practices Saarbrücken, Verlag, (2009)

8. V.P. Babintsev, V.A. Sapryka, Y.I. Serkina, G.F. Ushamirskaya. Eur. J. of Contemp. Educ 17(3), 284294 (2016)

9. E.A. McGibbon, Oppression: A Social Determinant of Health. Winnipeg: Fernwood Publ., (2012)

10. J. Kornai, Voprosy Ekonomiki 4. (2002).

11. E. Ugnich, A.Chernokozov, E.Filinkova, Advances in Social Science Education and Humanities Research, 97 (CILDIAH, 2017).

12. V.L. Zakovorotny, M.B. Flek, E.A. Ugnich, Intern. J. Econ. Perspect 10(4). (2016).

13. E.G.Popkova, V.I. Tinyakova, World Appl. Sci. J. 24(4), 467-475. (2013)

14. C. Freeman, Technology Policy and Economic Performance: Lesson from Japan. (Pinter Publ., 1987)

15. M. Laanpere. Tools and methods for Internet Usage in Estonia's system of general education. (Baltic IT review, 2000)

16. M. Laanpere, E. Matsak, J. Kippar. Integrating a concept mapping tool into a virtual learning environment: pedagogical and tehcnological challenges. In: Concept maps: theory, methodology, technology. Proceedings of CMC2006 (2006).

17. Ch. B. Jones. J. Futures Stud. 10(4), 6-8. (2006)

18. T. M. Crea, N. Sparnon. Democratizing education at the margins: faculty and practitioner perspectives on delivering online tertiary education for refugees. Intern. J. Educ. Tech. High. Educ. 14(43) (2017)

19. I. Rosenson. Fundamentals of design theory (SaintPetersburg, Peter, 2013)

20. J.T. Martins, M.B. Nunes, Intern. J. Educ. Man. 30(1), 2-19. (2016)

21. R. J. Beck. "What Are Learning Objects?" Learning Objects. University of Wisconsin-Milwaukee, (2009) 